\title{
Type II muscle fibre properties are not associated with balance recovery following large perturbations during walking in young and older adults
}

\author{
Christopher McCrum ${ }^{\star 1, \#}$, Lotte Grevendonk ${ }^{* 1}$, Gert Schaart ${ }^{1}$, Esther Moonen-Kornips ${ }^{1}$, \\ Johanna. A. Jörgensen ${ }^{1}$, Anne Gemmink ${ }^{1}$, Kenneth Meijer ${ }^{1}$, Joris Hoeks ${ }^{1}$
}

1Department of Nutrition and Movement Sciences, NUTRIM School of Nutrition and Translational Research in Metabolism, Maastricht University, Maastricht, The Netherlands

${ }^{*}$ Contributed equally

\#: Correspondence:

Christopher McCrum

Department of Nutrition and Movement Sciences

Maastricht University,

PO Box 616, Maastricht, 6200MD, The Netherlands

chris.mccrum@maastrichtuniversity.nl

\begin{abstract}
Falls among older adults are often attributed to declining muscle strength with ageing. Associations between muscle strength and balance control have been reported, but the evidence for, and key mechanisms of resistance exercise in fall prevention are unclear. No studies have directly examined the relationship between muscle fibre characteristics and reactive balance control. Here, we address whether or not Type II muscle fibre characteristics associate with reactive balance during walking in young and older adults with varying muscle fibre type composition. We analyse muscle biopsy-derived fibre characteristics and stability during a treadmill-based walking perturbation (trip-like) task of healthy young adults, healthy, normally active older adults, trained older adults and physically impaired older adults. We find no significant associations between Type II muscle fibre properties and reactive balance during walking, indicating that practitioners and researchers should consider more than just the muscle tissue properties when assessing and intervening on fall risk.
\end{abstract}




\section{Introduction}

Loss of muscle mass in humans after the age of 50 years is largely attributable to declines in lower body muscle mass [1], which has implications for mobility in older age. Specifically, the leg extensor muscle-tendon groups critical for gait [2-4] show reduced muscle strength and altered tendon mechanical properties in older, compared to younger adults [5-8]. Lower limb muscle strength [9-12], power [11,13,14] and quality $[15,16]$ have been associated with daily life falls incidence in older adults, although findings are not unequivocal [12,13,17-19]. The majority of falls in community-dwelling older adults occur following large balance disturbances (like trips and slips) during walking [20-27]. Small to moderate associations have been reported between lower limb muscle strength and balance recovery performance following laboratory-based lean-and-release [28-32], trip [33-36] and slip [37,38] perturbations simulating common causes of falls. Regarding interventions, there is weak or mixed evidence that general strength training alone can improve balance [39-41] and reduce falls [42,43], and whether a direct cause-effect relationship between muscle strength and balance performance exists has been questioned [44].

The loss in muscle strength and function with increasing age may occur due to muscle fibre atrophy and muscle fibre loss [45-48]. Age-related decline in muscle mass seems to be primarily attributable to an atrophy of specifically Type II muscle fibres [49-54]. Older age is also associated with a change in the expression of myosin heavy chain isoforms (MHC) in favor of slow MHC I, reflecting the shift towards a slower fibre type profile (Type I) and the selective atrophy of Type II fibres [54-56]. One study on older female participants with and without hip fractures reported that age and hip fracture history had significant individual and accumulating effects on Type II muscle fibre size (decreasing with age and fall-related hip fracture) [49]. Encouragingly, physical activity may prevent or slow this age-related atrophy of Type II fibres [52] and it has been reported that increases in muscle mass as a result of resistance exercise in old age is attributable to hypertrophy of Type II fibres specifically (and almost exclusively)[51]. In contrast, in endurance-trained older adults, greater proportions of Type I fibres have been observed when compared to strength-trained older adults, untrained older adults and untrained young individuals [57-59].

Together, these data suggest that muscle fibre characteristics may be an important factor in balance performance and falls. Despite this, there are no studies, to our knowledge, directly examining the relationship between muscle fibre characteristics and reactive balance control in the literature. In this study, we address for the first time whether or not Type II muscle fibre characteristics associate with reactive balance during walking in young and older adults with varying muscle fibre type composition. To do this, we analyse muscle biopsy-derived fibre characteristics and stability during a treadmill-based gait perturbation task of healthy young adults, healthy, normally active older adults, trained older adults and physically impaired older adults. Based on previous studies, we hypothesised that there would be a small to moderate relationship between Type II muscle fibre characteristics (size and proportion) and stability recovery following large perturbations during walking (number of recovery steps needed following a novel perturbation). We additionally explored these relationships after repeated perturbations to examine the potential role of Type II muscle fibre characteristics in adaptability of stability recovery responses.

\section{Methods}

\section{Participants}

The data and analyses in the current secondary analysis were part of a larger study $(n=59)$, which was approved by the institutional Medical Ethical Committee, conducted in accordance with the declaration of Helsinki and registered at clinicaltrials.gov (NCT03666013). All participants provided their written informed consent. Some data have been reported in our previous publication addressing different research questions [60]. For the current secondary 
analysis, the data of all participants who underwent muscle biopsies and completed the walking perturbation experiment in the larger study were included. This resulted in a sample of 52 participants including 14 young ( 7 male and 7 female) and 38 older ( 22 male and 16 female) individuals. Due to this being a secondary analysis, no formal power calculation was conducted to determine the sample size. However, sample sizes of 46 and 47 will achieve approximately $80 \%$ power with a significance level of 0.05 to detect Pearson and Spearman Correlation Coefficients of 0.4 , which we consider reasonable for the purpose of the current analysis.

Prior to inclusion, all participants underwent a medical screening that included a medical questionnaire, a physical examination by a physician, and an assessment of physical function by means of a Short Physical Performance Battery [61]. After screening, participants were assigned to the following groups: Young individuals with normal physical activity ( $Y, 20-30$ years), older adults with normal physical activity $(\mathrm{O}, 65-80$ years), trained older adults (TO, $65-80$ years) and older adults with impaired physical function (IO, $65-80$ years). Participants were considered normally physically active if they completed no more than one structured exercise session per week, whereas participants were considered trained if they engaged in at least 3 structured exercise sessions of at least 1 hour each per week for an uninterrupted period of at least one year. Participants were classified as older adults with impaired physical function (IO) in case of an SPPB score of $\leq 9$.

\section{Body Composition and Muscle Volume}

Body composition (fat and fat-free mass) was determined at $8 \mathrm{AM}$ after an overnight fast from $10 \mathrm{PM}$ the previous evening using air displacement plethysmography (BodPod $\AA$, COSMED, Inc., Rome, Italy) [62]. To measure muscle volume, a 3T whole body MRI scanner was used (Achieva 3T-X; Philips Healthcare, Best, The Netherlands). Participants were positioned in the supine position in the MR scanner (feet first) to determine muscle volume of the upper leg using the body coil. Subsequently, a series of T1-weighted images were acquired of the upper leg (slice thickness of $10 \mathrm{~mm}$, no gap between slices, in-plane resolution of $0.78 \times 0.78 \mathrm{~mm}$ ). A custom-written MATLAB script was used to automatically segment adipose and muscle tissue. Thereby each image was normalised, and a histogram calculated. Histogram peaks corresponding to muscle tissue grey values were summed up, resulting in the count of muscle pixels. Muscle volume was calculated by voxel size times the number of muscle pixels: Vol_muscle $=$ Vox_size ${ }^{*}$ __muscle pixels. Every slice was reviewed individually and in case of a clear notable deviation, a manual threshold correction for muscle grey values was performed. The muscle segmentation was performed in the consecutive slices between the starting point (tendon attachment) of the $m$. rectus femoris and of the $m$. gluteus maximus.

\section{Habitual physical activity}

Habitual physical activity was estimated using an ActivPAL activity monitor (PAL Technologies, Glasgow, Scotland) for five consecutive days, including two weekend days. The total amount of steps per day was measured, as well as the total stepping time in proportion to waking time, determined according to van der Berg et al. [63]. Stepping time (i. e., physical activity) was then further classified into high-intensity physical activity (HPA; minutes with a step frequency $>110$ steps/min in proportion to waking time) [64].

\section{Muscle Strength}

Maximum voluntary knee extension and flexion torque was measured using the Biodex System 3 Pro dynamometer (Biodex® Medical Systems, Inc., Shirley, NY, USA). Participants were stabilized with shoulder, leg, and abdominal straps to prevent compensatory movement 
and the test was performed with the left leg in all participants. Participants performed three $5 \mathrm{~s}$ maximal extensions and flexions with a 30 s rest period in between trials. The knee position was fixed at a $70^{\circ}$ angle. Maximal voluntary isometric knee-extensor and knee-flexor torque was defined as the average of the highest two out of three peak torques. Participants also performed 30 consecutive extension and flexion movements (range of motion 120 degrees/s). The peak torque of each extension and flexion was recorded and the maxima were defined as the highest peak. For both protocols, maximal torque was recorded in Newton-meters and corrected for bodyweight $(\mathrm{Nm} / \mathrm{kg})$.

\section{Muscle Biopsy and Fibre Typing}

A biopsy specimen was taken from the vastus lateralis muscle under local anesthesia $(1.0 \%$ lidocaine without epinephrine), according to the Bergström method [65]. Muscle tissue was immediately frozen in melting isopentane cooled with liquid nitrogen for immunohistochemistry and stored at $-80^{\circ} \mathrm{C}$ degrees until analysis. Fresh $5 \mu \mathrm{m}$-thick cryosections were treated for five minutes with $0.25 \%$ Triton X-100 in phosphate-buffered saline and incubated for 45 minutes at room temperature with a mouse monoclonal MHC1-antibody (A.4840; Developmental Studies Hybridoma Bank, lowa City, IO) and with the basal membrane marker laminin (L9393; Sigma, Zwijndrecht, The Netherlands). Thereafter, sections were incubated for 45 minutes with the appropriate secondary antibodies goat anti-mouse IgM AlexaFluor488 (A21042; Invitrogen Thermo Fisher, Breda, The Netherlands) and goat anti-rabbit IgG AlexaFluor555 (A21428; Invitrogen Thermo Fisher) and mounted with Mowiol. All sections were captured using a Nikon E800 fluorescence microscope (Nikon Instruments, Amsterdam, The Netherlands [66]) and images were analyzed in ImageJ [67]. Cell membranes were background corrected and threshold was set manually to create a binary image. Subsequently, the original cell membrane image (laminin staining) was added to the binary image of the cell membranes to check whether all cell membranes in the binary image were closed. If not, cell membranes were closed manually. Fibre size was determined by measuring the crosssectional area (CSA) and fibre type distribution was expressed as a percentage with respect to the number of fibres and as a percentage of CSA (\% fibre type I/II area relative to total CSA).

\section{Stability during Perturbed Walking}

The walking measurements were conducted using the Computer Assisted Rehabilitation Environment Extended (CAREN; Motekforce Link, Amsterdam). The system includes a dualbelt force plate-instrumented treadmill $(1000 \mathrm{~Hz})$, a 12 camera Vicon Nexus motion capture system $\left(100 \mathrm{~Hz}\right.$; Vicon Motion Systems, Oxford, UK) and a $180^{\circ}$ virtual environment providing optic flow. A safety harness connected to an overhead frame was worn by participants at all times. Six retroflective markers were attached to anatomical landmarks (C7, sacrum, left and right trochanter and left and right hallux).

Participants were already accustomed to the CAREN setup, as they had previously completed an instrumented six-minute walk test as part of the larger study. To further ensure participants were comfortable and familiarised to the measurement setup and conditions, the perturbation measurement session began with unrecorded fixed-speed walking trials of two minutes at speeds of $0.4 \mathrm{~m} / \mathrm{s}$ up to $1.8 \mathrm{~m} / \mathrm{s}$ in $0.2 \mathrm{~m} / \mathrm{s}$ increments. Following a break, the same fixed-speed walking trials were repeated and recorded. During another break, the data from these trials were used to calculate a stability-normalised walking speed for each participant individually for use in the subsequent walking perturbation trial, which was set for a margin of stability (MoS; see below; [68]) of $0.05 \mathrm{~m}$ as described previously [69], ensuring a comparable baseline walking stability for all groups [70-73]. Next, participants completed the perturbation trial which started with three to four minutes of unperturbed walking at the stability-normalised walking speed, followed by 10 unannounced unilateral treadmill belt acceleration perturbations (every 
30 to 90 seconds). The first and tenth accelerations were applied to the right leg, while the second to ninth accelerations were applied to the left leg as described previously [70,71]. Participants were told that they would complete a walking balance challenge and to try to continue walking as normally as possible. The participants were unaware of the specifics of the perturbations and no warnings or cues were given during the trial. For the current study, the first perturbations to each limb were analysed (Pert $1_{R}$ and Pert2 $L$ ), representing novel disturbances, as well as the ninth perturbation (final left leg perturbation; Pert9L) to indicate adaptation in gait following eight repeated perturbations.

Data processing was conducted in MATLAB (2016a, The MathWorks, Inc., Natick). The threedimensional coordinates of the markers were filtered using a low pass second order Butterworth filter (zero-phase) with a $12 \mathrm{~Hz}$ cut-off frequency. Foot touchdown and toe-off were detected using a combined method of force plate data (50 N threshold) and foot marker data [74], as described in detail previously [75]. The anteroposterior MoS at foot touchdown were calculated as the anteroposterior distance between the anterior boundary of the base of support (BoS) and the extrapolated centre of mass $\left(\mathrm{X}_{\mathrm{CoM}}\right)$ [68], adapted for our validated reduced kinematic model [76] and treadmill walking [77], in the same manner as our previous studies [69-72]. The MoS was calculated for the following steps: the mean MoS of the eleventh to second last step before each perturbation (Base); the final step before each perturbation (Pre); and the first eight recovery steps following each perturbation (Post1-8). In order to determine the number of steps to recover to baseline stability (up to the eighth recovery step), two methods were used. The first, as used in our previous studies [71-73], used a $0.05 \mathrm{~m}$ threshold - if the recovery step MoS value was within $0.05 \mathrm{~m}$ of the Base MoS, this was heuristically considered not meaningfully different to unperturbed baseline walking. The second method, rather than using a standard value for all participants, used an individual threshold of three standard deviations of the 10 pre-perturbation steps used to calculate Base. This accounted for those individuals with either much lower or higher variability in their unperturbed walking for whom the $0.05 \mathrm{~m}$ threshold might have been inappropriate. As there is no accepted standard for establishing the number of recovery steps, we have included and analysed both outcomes.

\section{Statistics}

Normality for all data was checked with Shapiro-Wilk tests, which determined whether parametric or non-parametric analyses would be used. Group differences in the parameters were assessed using either one-way ANOVAs with Tukey's multiple comparisons tests or Kruskal-Wallis tests with Dunn's multiple comparisons tests. All analyses involving the number of recovery steps included analyses using the standard $0.05 \mathrm{~m}$ threshold (Standard Threshold) and the individualised, three standard deviation threshold (Individual Threshold). Spearman correlations were conducted to assess the relationships between the recovery steps required by participants during Pert $1_{R}$, Pert $2_{L}$ and Pert9 ${ }_{L}$ and the muscle fibre properties (percentage of Type II fibres, mean Type II fibre CSA and the percentage of CSA taken up by Type II fibres). Spearman correlations were also conducted for the recovery steps required and the muscle volume and strength measures. Correlations with Pert $1_{\mathrm{R}}$ and Pert2L were used to determine associations with balance recovery following a novel perturbation (similar unexpected and unfamiliar situation to how falls occur in daily life) whereas associations with Pert9 $\llcorner$ were used to determine associations with adaptability of the stability recovery responses. a was set at 0.05 . Correlation coefficients were interpreted as follows: $0-0.1$ : Negligible; 0.1-0.3: Small; 0.3-0.5: Moderate; 0.5 and above: Large [78], although these may be overestimates in comparison to the field of gerontology, where there is evidence that Pearson's $r=0.12,0.20$, and .032 may better represent small medium and large effects [79]. Statistical analyses were conducted, and figures were prepared using GraphPad Prism version 9 for Windows (GraphPad Software, LLC, San Diego, California, USA). 


\section{Results}

\section{Participant Characteristics}

Of the 52 participants who were included in this study, one participant was excluded due to problems in both walking motion capture (noise and marker gaps) and muscle biopsy (not enough tissue), and a further three participants were excluded due to issues with the muscle biopsy (not enough useable tissue was collected). The remaining 48 participants' data were included in the analyses and their characteristics, arranged per group, are displayed in Table 1. Note that we did not specifically aim to have groups of a specific size, as the groups themselves were not related to our primary aims. Rather we wanted to achieve a sample that included a wide range of muscle fibre type characteristics and stability recovery performance that could provide insight into the associations between these parameters. Due to technical issues, walking data from Pert $1_{R}$ for one participant of group $O$, walking data from Pert2 $L$ for one participant of group TO and MRI-derived muscle volume data for one participant of group TO were excluded.

Groups $O$ and $Y$ possessed similar physical activity levels ( 10K steps/day and similar active time in high-intensity activities; Table 1). Group TO, in comparison were more active ( 13K steps/day and $4.9 \%$ active time was at high intensity; Table 1$)$ and were mainly involved in endurance sports and training, whereas Group IO were less active ( $7.5 \mathrm{~K}$ steps/day and $1.6 \%$ active time at high intensity; Table 1).

Table 1: Participant characteristics, presented as mean (SD).

\begin{tabular}{lllll}
\hline & $\begin{array}{l}\text { Young, normal } \\
\text { physical activity } \\
(\mathbf{Y})\end{array}$ & $\begin{array}{l}\text { Older adults, normal } \\
\text { physical activity (O) }\end{array}$ & $\begin{array}{l}\text { Physically impaired } \\
\text { older adults (10) }\end{array}$ & $\begin{array}{l}\text { Trained older } \\
\text { adults (TO) }\end{array}$ \\
\hline $\mathbf{N}$ & 12 & 16 & 3 & 17 \\
Male & 7 & 8 & 2 & 11 \\
Age [years] & $23.9(2.2)$ & $70.6(3)$ & $69.7(4.2)$ & $67.8(2.4)$ \\
BMI [kg/m & $22.4(3.3)$ & $25.8(3.4)$ & $28.4(1.8)$ & $23.8(1.8)$ \\
Height [cm] & $176(7.4)$ & $169(11.3)$ & $171(4.4)$ & $171.2(7.2)$ \\
Weight [kg] & $69.3(11.5)$ & $74.0(12.3)$ & $82.9(2.4)$ & $70(7.5)$ \\
$\begin{array}{l}\text { Fat mass [\%] } \\
\text { SPPB 4m walk }\end{array}$ & $22.6(8.4)$ & $33.3(9.5)$ & $37(10.7)$ & $25.9(8.1)$ \\
speed [m/s] & $1.1(0.2)$ & $1.2(0.2)$ & $1.0(0.3)$ & $1.3(0.2)$ \\
$\begin{array}{l}\text { SPPB Chair- } \\
\text { stand test [s] }\end{array}$ & $9.2(2.7)$ & $10.2(1.4)$ & $13.7(7.1)$ & $8.9(2.1)$ \\
$\begin{array}{l}\text { Steps/day } \\
\text { HPA time/wake } \\
\text { time (\%) }\end{array}$ & $10487(3134)$ & $10007(2885) \neq$ & $7594(1851)$ & $13604(6218)$ \\
$\begin{array}{l}\text { BMl: body mass index. SPPB: short physical performance battery.HPA: high intensity physical activity. *: One } \\
\text { participant excluded due to data processing issues. } \neq: \text { Two participants excluded due to data collection and analysis } \\
\text { issues. }\end{array}$ & & &
\end{tabular}




\section{Type I and II Muscle Fibre Characteristics}

In order to evaluate the muscle fibre type characteristics of the muscle biopsy samples, a mean (SD) of 454(260) muscle fibres were analysed per participant. Representative fluorescence microscope images used for fibre type analyses are displayed in Fig. 1. In order to explore the range in the characteristics, one-way ANOVAs were applied and did not reveal a significant group effect on Type I or II muscle fibre percentage $(F(3,44)=2.8, P=0.051)$, Type I fibre CSA $(F(3,44)=0.8, P=0.5)$ or Type II fibre $\operatorname{CSA}(F(3,44)=1.9, P=0.14)$, although group TO tended to have lower Type II fibre percentage (Fig. 1). A one-way ANOVA did reveal a significant effect of group on the percentage of total CSA taken up by Type I and II fibres $(F(3$, 44) $=4.5, P=0.007$ ), with Tukey's multiple comparisons tests revealing significantly lower values for group TO vs. $Y$ (adjusted $P=0.008$ ) and $O$ (adjusted $P=0.036$ ), as indicated in Fig. 1. While group comparisons were not always significant, these data confirm a range of muscle fibre type characteristics were present in our analysed participants, that there were no significant differences between groups $\mathrm{Y}$ and $\mathrm{O}$ and that group TO have an altered fibre type composition favouring Type I fibres. As can be seen in Fig. 1, Type II fibre mean CSA appeared to be lower in all older adult groups compared to group $Y$, despite a non-significant one-way ANOVA. Post hoc Mann Whitney tests comparing group $Y\left(n=12\right.$, Median $\left.=5477 \mu \mathrm{m}^{2}\right)$ with all older participants collapsed into one group $\left(n=36\right.$, Median $\left.=3509 \mu \mathrm{m}^{2}\right)$ and with Group $\mathrm{O}\left(\mathrm{n}=16\right.$, Median $\left.=3500 \mu \mathrm{m}^{2}\right)$ revealed significant differences in Type II fibre mean CSA $(\mathrm{U}=114, \mathrm{P}=0.014$ and $\mathrm{U}=49, \mathrm{P}=0.029$, respectively).

\section{Muscle Volume, Strength Characteristics and Perturbation Recovery Steps}

A one-way ANOVA did not reveal a significant effect of group on upper leg muscle volume $(F(3,43)=0.74, P=0.35)$. A significant group effect on peak isometric knee extension torque was found $(F(3,44)=3.06, P=0.038)$ with significantly lower values for group $O$ vs. $Y$ (adjusted $\mathrm{P}=0.0287)$. Kruskal-Wallis tests did not reveal a significant group effect on peak isometric knee flexion torque $(\mathrm{H}(3)=4.68, \mathrm{P}=0.197)$ but did reveal significant group effects on peak isokinetic knee extension $(\mathrm{H}(3)=25.96, \mathrm{P}<0.0001)$ and flexion $(\mathrm{H}(3)=25.98, \mathrm{P}<0.0001)$ torque, with significantly greater peak isokinetic knee extension torque in group $\mathrm{Y}$ vs. $\mathrm{O}$ (adjusted $\mathrm{P}<0.0001$ ), vs. IO (adjusted $\mathrm{P}=0.0024$ ) and vs. TO (adjusted $\mathrm{P}=0.0178$ ) and significantly greater peak isokinetic knee flexion torque in group $\mathrm{Y}$ vs. $\mathrm{O}$ (adjusted $\mathrm{P}<0.0001$ ) and vs. IO (adjusted $\mathrm{P}=0.0022$ ). Similar to the muscle fibre type characteristics, these data confirm a range of muscle strength values in our analysed participants. The muscle volume and strength data are displayed in the supplemental figures 1 and 2.

Kruskal-Wallis tests did not reveal a significant group effect on the number of recovery steps for any perturbation or recovery step threshold (Fig. 2; Standard Threshold: $H(3)=2.35, P=0.5$, $\mathrm{H}(3)=1.2, \mathrm{P}=0.75$ and $\mathrm{H}(3)=2.66, \mathrm{P}=0.45$ for Pert1 ${ }_{R}$, Pert2 $L_{L}$ and Pert9 ${ }_{L}$, respectively; Individual Threshold: $\mathrm{H}(3)=4.6, \mathrm{P}=0.2, \mathrm{H}(3)=2.68, \mathrm{P}=0.44$ and $\mathrm{H}(3)=0.36, \mathrm{P}=0.95$ for Pert ${ }_{\mathrm{R}}$, Pert2 $\mathrm{L}$ and Pert9 ${ }_{\mathrm{L}}$, respectively). However, as can be seen in Figure 2, a large range of numbers of recovery steps was observed across the participants. 

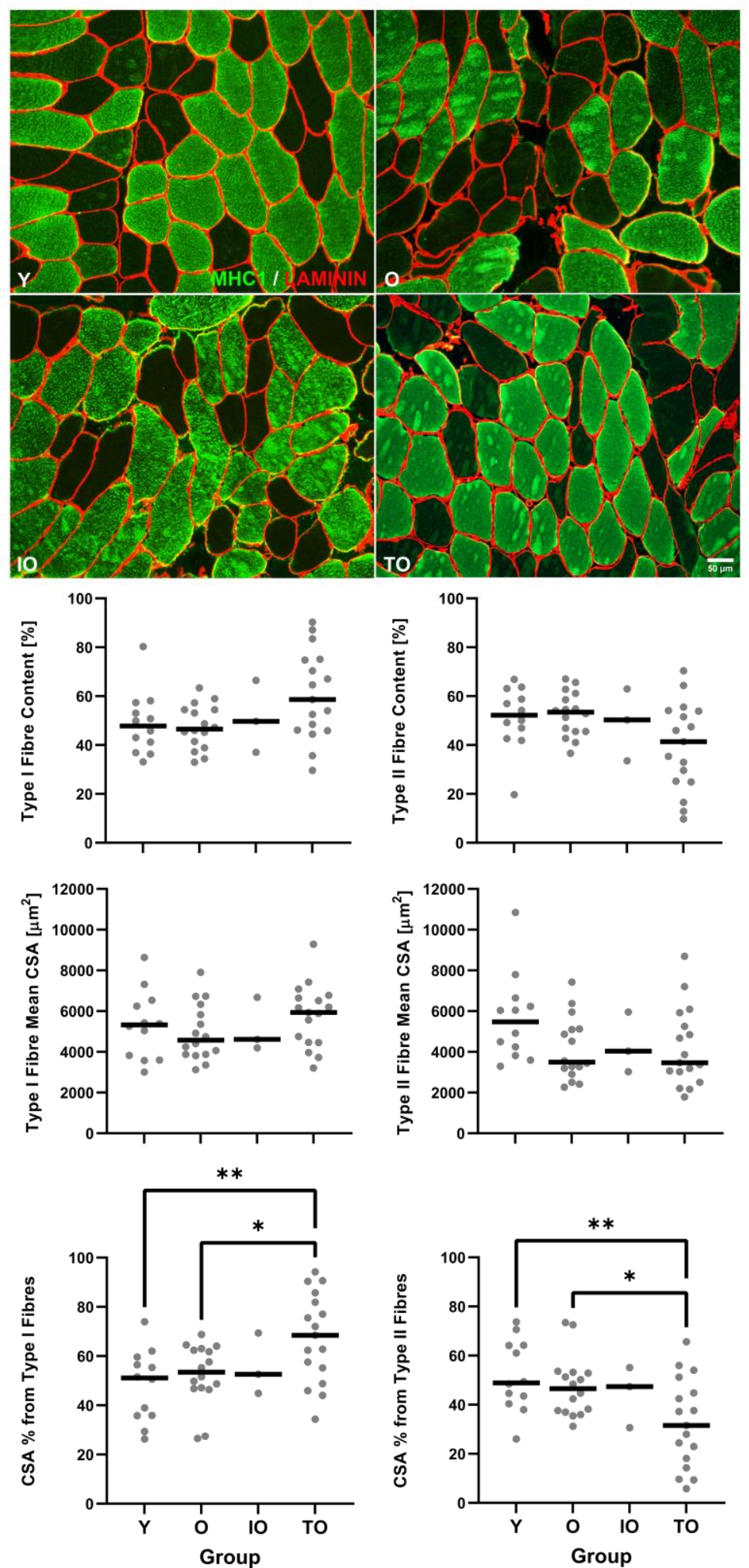

Figure 1: Top Panel: Representative fluorescence microscope images used for fibre type analyses from young adults $(Y)$, older adults with normal physical activity $(O)$, trained older adults (TO) and physically impaired older adults (IO). Basal membrane (laminin; red); type 1 fibres (MHC1; green) and type 2 fibres (no stain / black). Each participant shown has the median value of average fibre CSA within their group. Bottom Panel: Group median and individual Type I and II muscle fibre characteristics. *: $P=0.036^{* *}: P=0.008$ 

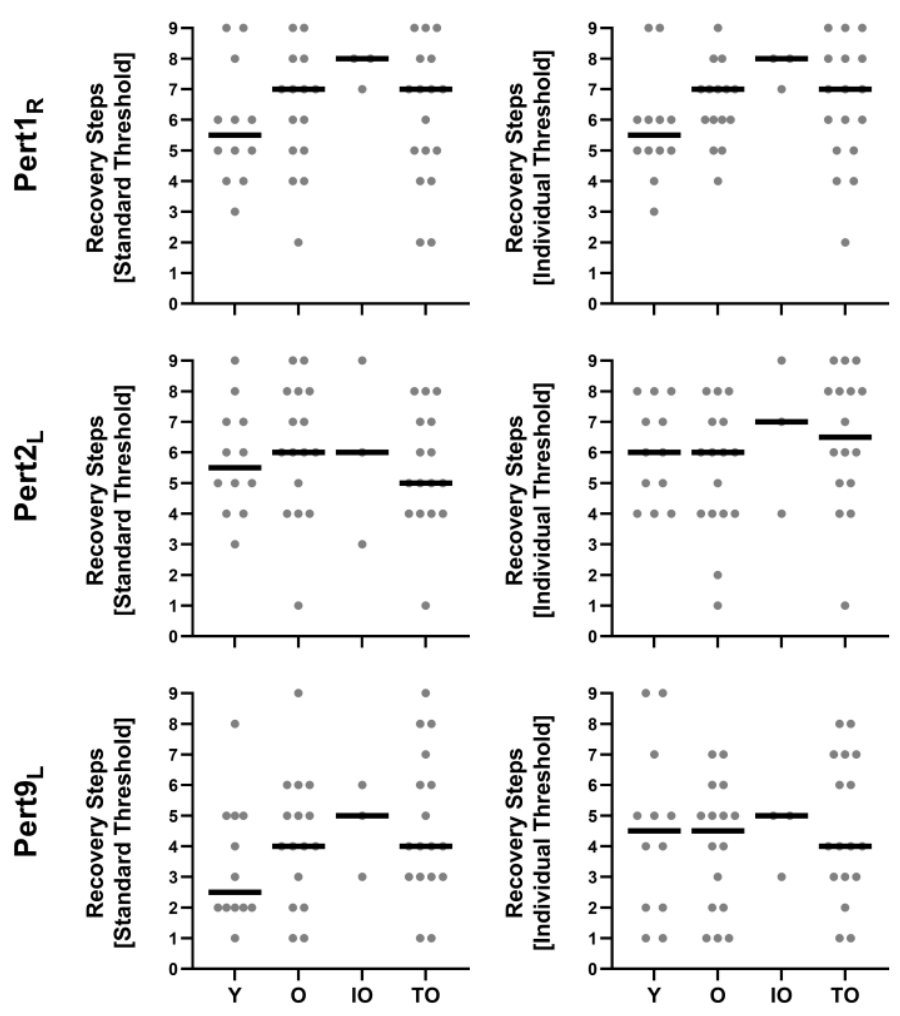

Figure 2: Group median and individual values for the number of recovery steps determined by the standard and individual thresholds for all the first perturbation to each leg (Pert1 ${ }_{R}$ and Pert $\left.2_{L}\right)$ and the final left leg perturbation (Pert9L) for young adults $(Y)$, older adults with normal physical activity $(O)$, trained older adults (TO) and physically impaired older adults (IO).

\section{No Associations between Type II Fibre Characteristics and Balance Recovery}

To test our hypothesis of a relationship between Type II muscle fibre characteristics (size and proportion) and stability recovery (number of recovery steps needed following a novel perturbation), Spearman correlations were conducted between these outcomes. These revealed no significant associations between the number of recovery steps following Pert $1_{R}$ and Pert2 $\mathrm{L}$ and the three Type II fibre characteristics: Type II fibre percentage, Type II fibre CSA and the percentage of total CSA taken up by Type II fibres (Table 2).

To provide further context for the muscle fibre characteristic associations, associations between the number of recovery steps and upper leg muscle volume and torque were also analysed. These Spearman correlations revealed no significant between upper leg muscle volume and the number of recovery steps following Pert $1_{R}$ and Pert2 $L$ (Supplementary Table 1). They revealed no significant associations between peak isometric and isokinetic knee extension and flexion torque and the number of recovery steps following Pert $1_{\mathrm{R}}$ and one (of 8) moderate, significant association for Pert2 $\mathrm{L}$ (significant for Peak Isometric Knee Flexion Torque; Supplementary Table 1). Note that to provide further insight into these relationships, we also ran post hoc Spearman correlations between the fibre type characteristics and the muscle volume and torque outcomes, which revealed significant correlations between all pairs of muscle volume and torque outcomes, four (out of five) significant correlations between Type II fibre CSA and the muscle volume and torque outcomes but no significant correlations between Type II muscle fibre content or percentage of CSA from Type II fibres and the muscle volume and torque outcomes (Supplementary Table 2). 


\section{No Associations between Type II Fibre Characteristics and Adapted Balance Recovery}

To explore the potential role of Type II muscle fibre characteristics in adaptability of stability recovery responses, associations between the recovery steps after eight repeated perturbations to the left leg (Pert9 ${ }_{\mathrm{L}}$ ) and the Type II muscle fibre characteristics were conducted. Spearman correlations revealed no significant associations between the number of recovery steps following Pert9 $\mathrm{L}$ and the three Type II fibre characteristics: Type II fibre percentage, Type II fibre CSA and the percentage of total CSA taken up by Type II fibres (Table 2).

Again, to provide additional information, associations between the Pert9 $\mathrm{L}$ recovery steps and muscle volume and torque were also conducted. In general agreement with the fibre type correlations, Spearman correlations revealed no significant associations between upper leg muscle volume and the number of recovery steps following Pert9 ${ }_{\mathrm{L}}$, and only one (of 8) moderate, significant associations between peak isometric and isokinetic knee extension and flexion torque and the number of recovery steps following Pert9 ${ }_{L}$ (Significant for Peak Isometric Knee Flexion Torque; Supplementary Table 1).

Table 2: Spearman Correlation Results for Recovery Steps and Type II Fibre Characteristics

\begin{tabular}{|c|c|c|c|c|c|c|c|}
\hline & & \multicolumn{2}{|c|}{ Pert1 $_{R}$} & \multicolumn{2}{|c|}{ Pert2 $\mathrm{L}$} & \multicolumn{2}{|c|}{ Pert9 ${ }_{L}$} \\
\hline & & $\begin{array}{l}\text { Standard } \\
\text { Threshold }\end{array}$ & $\begin{array}{l}\text { Individual } \\
\text { Threshold }\end{array}$ & $\begin{array}{l}\text { Standard } \\
\text { Threshold }\end{array}$ & $\begin{array}{l}\text { Individual } \\
\text { Threshold }\end{array}$ & $\begin{array}{l}\text { Standard } \\
\text { Threshold }\end{array}$ & $\begin{array}{l}\text { Individual } \\
\text { Threshold }\end{array}$ \\
\hline \multirow{3}{*}{$\begin{array}{l}\text { Type II Fibre } \\
\text { Content [\%] }\end{array}$} & Spearman $r$ & 0.127 & 0.159 & 0.202 & -0.036 & 0.043 & -0.111 \\
\hline & $95 \% \mathrm{Cl}$ & $\begin{array}{c}-0.175 \text { to } \\
0.407\end{array}$ & $\begin{array}{c}-0.143 \text { to } \\
0.434\end{array}$ & $\begin{array}{c}-0.100 \text { to } \\
0.469\end{array}$ & $\begin{array}{c}-0.327 \text { to } \\
0.262\end{array}$ & $\begin{array}{c}-0.252 \text { to } \\
0.331\end{array}$ & $\begin{array}{c}-0.391 \text { to } \\
0.187\end{array}$ \\
\hline & $P$ & 0.395 & 0.286 & 0.174 & 0.812 & 0.771 & 0.452 \\
\hline \multirow{3}{*}{$\begin{array}{c}\text { Type II Fibre } \\
\text { Mean CSA } \\
{\left[\mu \mathrm{m}^{2}\right]}\end{array}$} & Spearman $r$ & -0.026 & -0.027 & 0.103 & 0.056 & -0.214 & -0.048 \\
\hline & $95 \% \mathrm{Cl}$ & $\begin{array}{c}-0.319 \text { to } \\
0.271\end{array}$ & $\begin{array}{c}-0.320 \text { to } \\
0.270\end{array}$ & $\begin{array}{c}-0.198 \text { to } \\
0.387\end{array}$ & $\begin{array}{c}-0.243 \text { to } \\
0.345\end{array}$ & $\begin{array}{c}-0.476 \text { to } \\
0.083\end{array}$ & $\begin{array}{l}-0.336 \text { to } \\
0.247\end{array}$ \\
\hline & $P$ & 0.861 & 0.856 & 0.490 & 0.710 & 0.144 & 0.745 \\
\hline \multirow{3}{*}{$\begin{array}{l}\text { CSA \% from } \\
\text { Type II Fibres }\end{array}$} & Spearman $r$ & 0.143 & 0.120 & 0.194 & -0.125 & -0.085 & -0.161 \\
\hline & $95 \% \mathrm{Cl}$ & $\begin{array}{c}-0.159 \text { to } \\
0.420\end{array}$ & $\begin{array}{c}-0.182 \text { to } \\
0.401\end{array}$ & $\begin{array}{c}-0.107 \text { to } \\
0.463\end{array}$ & $\begin{array}{c}-0.405 \text { to } \\
0.177\end{array}$ & $\begin{array}{c}-0.367 \text { to } \\
0.213\end{array}$ & $\begin{array}{c}-0.433 \text { to } \\
0.137\end{array}$ \\
\hline & $P$ & 0.338 & 0.422 & 0.191 & 0.404 & 0.568 & 0.273 \\
\hline
\end{tabular}

\section{Discussion}

In this study, we aimed to provide the first data on whether or not Type II muscle fibre characteristics associate with reactive balance during walking in young and older adults with varying muscle fibre type composition. We hypothesised that there would be a small to moderate relationship between Type II muscle fibre characteristics (size and proportion) and stability recovery (number of recovery steps needed following a novel perturbation). We conducted correlation analyses on our data from 48 young and older participants, with varying physical activity levels, muscle fibre type characteristics, muscle volume and strength, as well as stability recovery performance, and were not able to confirm this hypothesis, as we did not observe such correlations. The results of our secondary, exploratory correlations with muscle volume and strength generally aligned with the fibre type characteristic results, since associations between these parameters and stability recovery were also virtually absent.

The current study found no significant differences in muscle fibre size in older adults compared to younger adults. Thus, we found no age-related differences between young and older 
participants who were not engaged in structured physical exercise but possessed comparable physical activity levels ( 10K steps/day) well above the general recommendation [64]. These results appear in contrast to previous studies reporting a substantial decrease in muscle fibre size, especially in Type II fibres, with age $[50,51,53]$. However, most of these studies did not measure and control for an age-related decrease in physical activity [50,51,53], which could explain muscle fibre atrophy [59]. In line with our data, St-Jean-Pelletier et al. [52] observed an age-related decrease in muscle Type II fibre size in sedentary middle-aged and older adults ( $\sim 7 \mathrm{~K}$ vs. $\sim 6.3 \mathrm{~K}$ steps/day on average) but not in physically active middle-aged and older adults ( $\sim 12.9 \mathrm{~K}$ vs. $\sim 12.6 \mathrm{~K}$ steps/day). These results further support the hypothesis that muscle fibre atrophy is not simply a function of ageing per se but might also be driven by age-related physical inactivity and immobilization. However, it should be kept in mind that while the ANOVA was not significant, our post hoc analyses comparing the young adults with all older adults and with group $\mathrm{O}$ each found a significant effect of age on Type II fibre CSA (Hedges $g=0.82$ and $g=0.84$, respectively).

In the present study, the relative proportion of Type I muscle fibres was larger in endurancetrained older adults when compared to older adults with normal physical activity levels and young individuals. Although individual studies have shown conflicting findings regarding muscle fibre type distribution between young and older endurance-trained individuals [80,81], our results are in line with evidence indicating greater proportions of Type I fibres in endurance-trained older adults when compared to untrained older adults and untrained young individuals [57-59]. While evidence suggests long-term strength training provides a strong stimulus for the preservation of the structural and mechanical characteristics of skeletal muscle during ageing [54,82], it remains unclear to what extent aerobic training alone can counteract these age-related changes $[80,83,84]$. However, endurance athletes may benefit from other adaptations that play a role in stability. One previous study reported that in a mixed group of older and younger adults, those who were recreational runners performed better on a forward falling task than the non-active participants, despite similar muscle strength values [30]. The authors suggested that runners frequently manage the stability of their body position during running and may therefore be better able to perform such destabilising tasks [30]. In our study, of the 17 participants in group TO, eight participated in regular running and a further two participated in badminton and tennis, which also involve multidirectional stepping and change of direction, and these individuals may have compensated their reduction in Type II fibre size and number with relatively more refined stability control.

The literature is currently mixed regarding the role of muscle strength in balance and falls [913,17,39-42]. Despite this, small to moderate associations between lower limb muscle strength and balance recovery performance following laboratory-based perturbations [28-38] led us to our hypothesis of a small to moderate relationship between Type II muscle fibre properties and balance recovery performance from a sudden walking perturbation. Our results suggest that the muscle fibre properties themselves are not critical factors for reactive balance recovery during walking, due to the lack of correlations, the inconsistent direction of the (nonsignificant) correlations, as well as the fact that the trained older group did not require a significantly different number of recovery steps, despite a significantly different proportion of the muscle fibre CSA coming from Type II fibres. In order to check if the younger adults' data were unduly influencing these results, we repeated the Spearmen correlation analyses post hoc with only the older participants included and these demonstrated similar results, with only one of the 18 associations being significant (Supplementary Table 3). Our collective muscle volume and strength correlation results were also mostly not statistically significant. These results may, to some extent, explain some of the mixed findings in the literature. Strength testing or training that primarily targets the muscle tissue properties and neglects other factors (such as motor coordination, response/movement speed, functionally relevant movements, among others; see Tieland et al. [47] and Hunter et al. [85] for reviews) may not capture critical elements of muscle function relevant for reactive balance control. That being said, the success of the recovery actions may not critically depend on maximal muscle strength at all. For example, one biomechanical modelling study found that, for backward balance loss, there is 
quite some overlap in the feasible regions for balance recovery during simulations with strength characteristics of young and older adults and recovery was only limited by strength during very short or very long recovery steps [86]. This is also supported by other studies demonstrating that older adults can improve their balance recovery responses to a level similar to young adults when repeatedly exposed to perturbations (acutely and over longer time periods), without changes in muscle strength [36,87]. As falls among community-dwelling older adults usually occur during dynamic movement [20-27], specificity of both strength and balance assessment and training should be key considerations in fall prevention.

\section{Study Limitations}

Some limitations of the current study should be considered. Regarding the walking perturbation protocol, our participants were informed that they would complete a walking balance challenge but were unaware of the specifics of the perturbations and no warnings or cues were given during the trial. However, beneficial effects of increased awareness of perturbations on stability recovery performance following trips have been shown $[88,89]$, even when the specifics are unknown. This may have resulted in better balance recovery performance than might be expected in natural settings. Regarding our outcome measure, the number of recovery steps, this is not a standard measure of balance recovery following perturbations to walking. However, no gold-standard outcome measure exists for this purpose. Other possibilities would be to use specific biomechanical variables such as the margin of stability or trunk lean at a specific time point. However, due to the heterogeneity in the balance recovery responses to such perturbations, using such specific measures at specific time points has limitations when trying to capture "overall" balance recovery during walking. We feel that the current measure gives a more general overall indicator that is more robust to individual differences in response behaviour. It should also be kept in mind that our muscle biopsies came from the vastus lateralis muscle which is not necessarily the most critical muscle for gait [2-4] (although it likely plays an important role in leg extension and energy absorption during the initial recovery steps) nor entirely representative of the fibre type properties from other lower limb muscles [90-92]. Finally, one potential limitation is the exploratory nature of some of the correlations and the lack of a priori correction for multiple comparisons. In general, despite the relatively high number of correlations performed, the lack of significance and the inconsistency in the direction of the correlations leads us to believe that our conclusions are justified and not dependent on spurious correlations (significant or not).

\section{Conclusions}

The current results indicate that Type II muscle fibre properties (proportion and dimensions) are not significantly associated with reactive balance recovery following perturbations to walking in young and older adults. Upper leg muscle volume and knee flexion and extension torque also failed to show a significant relationship with reactive balance recovery. These results have implications for muscle strength testing and training in fall prevention, as it appears that the muscle tissue properties are not key factors for balance recovery. 
bioRxiv preprint doi: https://doi.org/10.1101/2021.11.26.470167; this version posted November 27, 2021. The copyright holder for this preprint (which was not certified by peer review) is the author/funder, who has granted bioRxiv a license to display the preprint in perpetuity. It is made available under aCC-BY 4.0 International license.

\section{Acknowledgements}

The authors thank Matthijs Hesselink for helpful discussions regarding the fibre type analysis, Tim Snijders for helpful comments and discussion on an earlier draft of the manuscript, Wouter Bijnens for assistance with the walking measurements, Paul Willems for technical support and Pascal Rense and Colin Dohmen for assistance with participant recruitment and various measurements.

\section{Author Contributions}

CM: Conceptualisation, Data Curation, Formal Analysis, Investigation, Methodology, Visualisation, Writing Original Draft, Writing - Reviewing \& Editing.

LG: Conceptualisation, Data Curation, Funding Acquisition, Investigation, Project Administration, Writing - Original Draft, Writing - Reviewing \& Editing.

GS: Investigation, Visualisation, Writing - Reviewing \& Editing.

EKM: Investigation, Writing - Reviewing \& Editing.

JAJ: Investigation, Writing - Reviewing \& Editing.

AG: Investigation, Software, Writing - Reviewing \& Editing.

KM: Conceptualisation, Resources, Supervision, Writing - Reviewing \& Editing.

$\mathrm{JH}$ : Conceptualisation, Funding Acquisition, Project Administration, Resources, Supervision, Writing - Reviewing \& Editing.

\section{Funding}

CM was financially supported by the NUTRIM Graduate Programme of Maastricht University Medical Centre+. LG and JH are financially supported by the TIFN research program Mitochondrial Health (ALWTF.2015.5). The project is partly organised by and executed under the auspices of TiFN, a public-private partnership on precompetitive research in food and nutrition.

\section{Competing Interests}

The authors declare no competing interests. Danone Nutricia Research, Friesland Campina, the Netherlands Organisation for Scientific Research and the Top-sector Agri\&Food are sponsors of the TIFN program and partly financed the project. They had no role in data collection and analysis, and the decision to publish.

\section{References}

1. Janssen I, Heymsfield SB, Wang Z, Ross R (2000) Skeletal muscle mass and distribution in 468 men and women aged 18-88 yr. J Appl Physiol 89 (1):81-88. doi:10.1152/jappl.2000.89.1.81

2. Kulmala JP, Korhonen MT, Ruggiero L, Kuitunen S, Suominen H, Heinonen A, Mikkola A, Avela J (2016) Walking and Running Require Greater Effort from Ankle than Knee Extensor Muscles. Med Sci Sports Exerc. doi:10.1249/mss.0000000000001020

3. Kulmala JP, Korhonen MT, Kuitunen S, Suominen H, Heinonen A, Mikkola A, Avela J (2014) Which muscles compromise human locomotor performance with age? J R Soc Interface 11 (100):20140858. doi:10.1098/rsif.2014.0858

4. Pandy MG, Andriacchi TP (2010) Muscle and joint function in human locomotion. Annu Rev Biomed Eng 12:401433. doi:10.1146/annurev-bioeng-070909-105259

5. McCrum C, Leow P, Epro G, Konig M, Meijer K, Karamanidis K (2018) Alterations in Leg Extensor MuscleTendon Unit Biomechanical Properties With Ageing and Mechanical Loading. Front Physiol 9 (150):150. doi:10.3389/fphys.2018.00150

6. Stenroth L, Peltonen J, Cronin NJ, Sipila S, Finni T (2012) Age-related differences in Achilles tendon properties and triceps surae muscle architecture in vivo. J Appl Physiol 113 (10):1537-1544. doi:10.1152/japplphysiol.00782.2012

7. Onambele GL, Narici MV, Maganaris CN (2006) Calf muscle-tendon properties and postural balance in old age. J Appl Physiol 100 (6):2048-2056. doi:10.1152/japplphysiol.01442.2005

8. Mademli L, Arampatzis A, Karamanidis K (2008) Dynamic stability control in forward falls: postural corrections after muscle fatigue in young and older adults. Eur J Appl Physiol 103 (3):295-306. doi:10.1007/s00421-0080704-z

9. De Rekeneire N, Visser M, Peila R, Nevitt MC, Cauley JA, Tylavsky FA, Simonsick EM, Harris TB (2003) Is a Fall Just a Fall: Correlates of Falling in Healthy Older Persons. The Health, Aging and Body Composition Study. J Am Geriatr Soc 51 (6):841-846. doi:10.1046/j.1365-2389.2003.51267.x

10. Cattagni T, Scaglioni G, Laroche D, Van Hoecke J, Gremeaux V, Martin A (2014) Ankle muscle strength discriminates fallers from non-fallers. Front Aging Neurosci 6:336. doi:10.3389/fnagi.2014.00336 
bioRxiv preprint doi: https://doi.org/10.1101/2021.11.26.470167; this version posted November 27, 2021. The copyright holder for this preprint (which was not certified by peer review) is the author/funder, who has granted bioRxiv a license to display the preprint in perpetuity. It is made available under aCC-BY 4.0 International license.

11. Perry MC, Carville SF, Smith ICH, Rutherford OM, Newham DJ (2007) Strength, power output and symmetry of leg muscles: effect of age and history of falling. Eur J Appl Physiol 100 (5):553-561. doi:10.1007/s00421006-0247-0

12. LaRoche DP, Cremin KA, Greenleaf B, Croce RV (2010) Rapid torque development in older female fallers and nonfallers: A comparison across lower-extremity muscles. J Electromyogr Kinesiol 20 (3):482-488. doi:10.1016/j.jelekin.2009.08.004

13. Kamo T, Asahi R, Azami M, Ogihara H, Ikeda T, Suzuki K, Nishida Y (2019) Rate of torque development and the risk of falls among community dwelling older adults in Japan. Gait Posture 72:28-33. doi:10.1016/j.gaitpost.2019.05.019

14. Skelton DA, Kennedy J, Rutherford OM (2002) Explosive power and asymmetry in leg muscle function in frequent fallers and non-fallers aged over 65. Age Ageing 31 (2):119-125. doi:10.1093/ageing/31.2.119

15. Gadelha AB, Neri SGR, Nobrega OT, Pereira JC, Bottaro M, Fonseca A, Lima RM (2018) Muscle quality is associated with dynamic balance, fear of falling, and falls in older women. Exp Gerontol 104:1-6. doi:10.1016/j.exger.2018.01.003

16. Gadelha AB, Neri SGR, Bottaro M, Lima RM (2018) The relationship between muscle quality and incidence of falls in older community-dwelling women: An 18-month follow-up study. Exp Gerontol 110:241-246. doi:10.1016/j.exger.2018.06.018

17. Melzer I, Benjuya N, Kaplanski J (2004) Postural stability in the elderly: a comparison between fallers and nonfallers. Age Ageing 33 (6):602-607. doi:10.1093/ageing/afh218

18. Lunt E, Ong T, Gordon AL, Greenhaff PL, Gladman JRF (2021) The clinical usefulness of muscle mass and strength measures in older people: a systematic review. Age Ageing 50 (1):88-95. doi:10.1093/ageing/afaa123

19. Porto JM, Cangussu-Oliveira LM, Freire Júnior RC, Vieira FT, Capato LL, de Oliveira BGM, de Abreu DCC (2021) Relationship Between Lower Limb Muscle Strength and Future Falls Among Community-Dwelling Older Adults With No History of Falls: A Prospective 1-Year Study. J Appl Gerontol 40 (3):339-346. doi:10.1177/0733464820932778

20. Berg WP, Alessio HM, Mills EM, Tong C (1997) Circumstances and consequences of falls in independent community-dwelling older adults. Age Ageing 26 (4):261-268. doi:10.1093/ageing/26.4.261

21. Tinetti ME, Speechley M, Ginter SF (1988) Risk factors for falls among elderly persons living in the community. N Engl J Med 319 (26):1701-1707. doi:10.1056/NEJM198812293192604

22. Sheldon JH (1960) On the Natural History of Falls in Old Age. Br Med J 2 (5214):1685-1690. doi:10.1136/bmj.2.5214.1685

23. Lord SR, Ward JA, Williams P, Anstey KJ (1993) An epidemiological study of falls in older community-dwelling women: the Randwick falls and fractures study. Aust J Public Health 17 (3):240-245. doi:10.1111/j.17536405.1993.tb00143.x

24. Niino N, Tsuzuku S, Ando F, Shimokata H (2000) Frequencies and circumstances of falls in the National Institute for Longevity Sciences, Longitudinal Study of Aging (NILS-LSA). J Epidemiol 10 (1 Suppl):S90-94. doi:10.2188/jea.10.1sup_90

25. Talbot LA, Musiol RJ, Witham EK, Metter EJ (2005) Falls in young, middle-aged and older community dwelling adults: perceived cause, environmental factors and injury. BMC Public Health 5:86. doi:10.1186/1471-2458-586

26. Crenshaw JR, Bernhardt KA, Achenbach SJ, Atkinson EJ, Khosla S, Kaufman KR, Amin S (2017) The circumstances, orientations, and impact locations of falls in community-dwelling older women. Arch Gerontol Geriatr 73:240-247. doi:10.1016/j.archger.2017.07.011

27. McCrum C (2019) A Trip to Remember: Assessing and Improving Walking Stability in Older Adults. Maastricht University, Gildeprint Drukkerijen. doi:10.26481/dis.20191219cm

28. Grabiner MD, Owings TM, Pavol MJ (2005) Lower extremity strength plays only a small role in determining the maximum recoverable lean angle in older adults. J Gerontol A Biol Sci Med Sci 60 (11):1447-1450. doi:10.1093/gerona/60.11.1447

29. Karamanidis K, Arampatzis A, Mademli L (2008) Age-related deficit in dynamic stability control after forward falls is affected by muscle strength and tendon stiffness. J Electromyogr Kinesiol 18 (6):980-989. doi:10.1016/j.jelekin.2007.04.003

30. Karamanidis K, Arampatzis A (2007) Age-related degeneration in leg-extensor muscle-tendon units decreases recovery performance after a forward fall: compensation with running experience. Eur J Appl Physiol 99 (1):7385. doi:10.1007/s00421-006-0318-2

31. Carty CP, Barrett RS, Cronin NJ, Lichtwark GA, Mills PM (2012) Lower limb muscle weakness predicts use of a multiple- versus single-step strategy to recover from forward loss of balance in older adults. J Gerontol A Biol Sci Med Sci 67 (11):1246-1252. doi:10.1093/gerona/gls149

32. Carty CP, Cronin NJ, Lichtwark GA, Mills PM, Barrett RS (2012) Lower limb muscle moments and power during recovery from forward loss of balance in male and female single and multiple steppers. Clin Biomech 27 (10):1031-1037. doi:10.1016/j.clinbiomech.2012.07.009

33. Pavol MJ, Owings TM, Foley KT, Grabiner MD (2002) Influence of lower extremity strength of healthy older adults on the outcome of an induced trip. J Am Geriatr Soc 50 (2):256-262

34. Pijnappels M, van der Burg PJ, Reeves ND, van Dieen JH (2008) Identification of elderly fallers by muscle strength measures. Eur J Appl Physiol 102 (5):585-592. doi:10.1007/s00421-007-0613-6

35. Pijnappels M, Bobbert MF, van Dieen JH (2005) Push-off reactions in recovery after tripping discriminate young subjects, older non-fallers and older fallers. Gait Posture 21 (4):388-394. doi:10.1016/j.gaitpost.2004.04.009 
bioRxiv preprint doi: https://doi.org/10.1101/2021.11.26.470167; this version posted November 27, 2021. The copyright holder for this preprint (which was not certified by peer review) is the author/funder, who has granted bioRxiv a license to display the preprint in perpetuity. It is made available under aCC-BY 4.0 International license.

36. Epro G, McCrum C, Mierau A, Leyendecker M, Brüggemann GP, Karamanidis K (2018) Effects of triceps surae muscle strength and tendon stiffness on the reactive dynamic stability and adaptability of older female adults during perturbed walking. J Appl Physiol 124 (6):1541-1549. doi:10.1152/japplphysiol.00545.2017

37. Ding L, Yang F (2016) Muscle weakness is related to slip-initiated falls among community-dwelling older adults. J Biomech 49 (2):238-243. doi:10.1016/j.jbiomech.2015.12.009

38. Han L, Yang $F$ (2015) Strength or power, which is more important to prevent slip-related falls? Hum Mov Sci 44:192-200. doi:10.1016/j.humov.2015.09.001

39. Orr R, Raymond J, Fiatarone Singh M (2008) Efficacy of progressive resistance training on balance performance in older adults : a systematic review of randomized controlled trials. Sports Med 38 (4):317-343. doi:10.2165/00007256-200838040-00004

40. Howe TE, Rochester L, Neil F, Skelton DA, Ballinger C (2011) Exercise for improving balance in older people. Cochrane Database Syst Rev (11):Cd004963. doi:10.1002/14651858.CD004963.pub3

41. Horlings CG, van Engelen BG, Allum JH, Bloem BR (2008) A weak balance: the contribution of muscle weakness to postural instability and falls. Nat Clin Pract Neurol 4 (9):504-515. doi:10.1038/ncpneuro0886

42. Sherrington C, Fairhall NJ, Wallbank GK, Tiedemann A, Michaleff ZA, Howard K, Clemson L, Hopewell S, Lamb SE (2019) Exercise for preventing falls in older people living in the community. Cochrane Database Syst Rev 1:CD012424. doi:10.1002/14651858.CD012424.pub2

43. Sibley KM, Thomas SM, Veroniki AA, Rodrigues M, Hamid JS, Lachance CC, Cogo E, Khan PA, Riva JJ, Thavorn K, MacDonald H, Holroyd-Leduc J, Feldman F, Kerr GD, Jaglal SB, Straus SE, Tricco AC (2021) Comparative effectiveness of exercise interventions for preventing falls in older adults: A secondary analysis of a systematic review with network meta-analysis. Exp Gerontol 143:111151. doi:10.1016/j.exger.2020.111151

44. Orr R (2010) Contribution of muscle weakness to postural instability in the elderly. A systematic review. Eur J Phys Rehabil Med 46 (2):183-220

45. Wilkinson DJ, Piasecki M, Atherton PJ (2018) The age-related loss of skeletal muscle mass and function: Measurement and physiology of muscle fibre atrophy and muscle fibre loss in humans. Ageing Res Rev 47:123132. doi:10.1016/j.arr.2018.07.005

46. Deschenes MR (2004) Effects of Aging on Muscle Fibre Type and Size. Sports Med 34 (12):809-824. doi:10.2165/00007256-200434120-00002

47. Tieland M, Trouwborst I, Clark BC (2018) Skeletal muscle performance and ageing. J Cachexia Sarcopenia Muscle 9 (1):3-19. doi:10.1002/jcsm.12238

48. Mitchell WK, Atherton PJ, Williams J, Larvin M, Lund JN, Narici M (2012) Sarcopenia, Dynapenia, and the Impact of Advancing Age on Human Skeletal Muscle Size and Strength; a Quantitative Review. Front Physiol 3. doi:10.3389/fphys.2012.00260

49. Kramer IF, Snijders T, Smeets JSJ, Leenders M, van Kranenburg J, den Hoed M, Verdijk LB, Poeze M, van Loon LJC (2017) Extensive Type II Muscle Fiber Atrophy in Elderly Female Hip Fracture Patients. J Gerontol A Biol Sci Med Sci 72 (10):1369-1375. doi:10.1093/gerona/glw253

50. McPhee JS, Cameron J, Maden-Wilkinson T, Piasecki M, Yap MH, Jones DA, Degens H (2018) The Contributions of Fiber Atrophy, Fiber Loss, In Situ Specific Force, and Voluntary Activation to Weakness in Sarcopenia. J Gerontol A Biol Sci Med Sci 73 (10):1287-1294. doi:10.1093/gerona/gly040

51. Nilwik R, Snijders T, Leenders M, Groen BBL, van Kranenburg J, Verdijk LB, van Loon LJC (2013) The decline in skeletal muscle mass with aging is mainly attributed to a reduction in type II muscle fiber size. Exp Gerontol 48 (5):492-498. doi:10.1016/j.exger.2013.02.012

52. St-Jean-Pelletier F, Pion CH, Leduc-Gaudet J-P, Sgarioto N, Zovilé I, Barbat-Artigas S, Reynaud O, Alkaterji F, Lemieux FC, Grenon A, Gaudreau P, Hepple RT, Chevalier S, Belanger M, Morais JA, Aubertin-Leheudre M, Gouspillou $G$ (2017) The impact of ageing, physical activity, and pre-frailty on skeletal muscle phenotype, mitochondrial content, and intramyocellular lipids in men. J Cachexia Sarcopenia Muscle 8 (2):213-228. doi:10.1002/jcsm.12139

53. Lee W-S, Cheung W-H, Qin L, Tang N, Leung K-S (2006) Age-associated Decrease of Type IIA/B Human Skeletal Muscle Fibers. Clin Orthop Relat Res 450:231-237. doi:10.1097/01.blo.0000218757.97063.21

54. Klitgaard H, Mantoni M, Schiaffino S, Ausoni S, Gorza L, Laurent-Winter C, Schnohr P, Saltin B (1990) Function, morphology and protein expression of ageing skeletal muscle: a cross-sectional study of elderly men with different training backgrounds. Acta Physiol Scand 140 (1):41-54. doi:10.1111/j.1748-1716.1990.tb08974.x

55. Hameed M, Orrell RW, Cobbold M, Goldspink G, Harridge SD (2003) Expression of IGF-I splice variants in young and old human skeletal muscle after high resistance exercise. J Physiol 547 (Pt 1):247-254. doi:10.1113/jphysiol.2002.032136

56. Short KR, Vittone JL, Bigelow ML, Proctor DN, Coenen-Schimke JM, Rys P, Nair KS (2005) Changes in myosin heavy chain mRNA and protein expression in human skeletal muscle with age and endurance exercise training. J Appl Physiol 99 (1):95-102. doi:10.1152/japplphysiol.00129.2005

57. Aagaard P, Magnusson PS, Larsson B, Kjaer M, Krustrup P (2007) Mechanical muscle function, morphology, and fiber type in lifelong trained elderly. Med Sci Sports Exerc 39 (11):1989-1996. doi:10.1249/mss.0b013e31814fb402

58. Mackey AL, Karlsen A, Couppé C, Mikkelsen UR, Nielsen RH, Magnusson SP, Kjaer M (2014) Differential satellite cell density of type I and II fibres with lifelong endurance running in old men. Acta Physiol (Oxf) 210 (3):612-627. doi:10.1111/apha.12195

59. Mosole S, Carraro U, Kern H, Loefler S, Fruhmann H, Vogelauer M, Burggraf S, Mayr W, Krenn M, PaternostroSluga T, Hamar D, Cvecka J, Sedliak M, Tirpakova V, Sarabon N, Musarò A, Sandri M, Protasi F, Nori A, Pond 
bioRxiv preprint doi: https://doi.org/10.1101/2021.11.26.470167; this version posted November 27, 2021. The copyright holder for this preprint (which was not certified by peer review) is the author/funder, who has granted bioRxiv a license to display the preprint in perpetuity. It is made available under aCC-BY 4.0 International license.

A, Zampieri S (2014) Long-term high-level exercise promotes muscle reinnervation with age. J Neuropathol Exp Neurol 73 (4):284-294. doi:10.1097/nen.0000000000000032

60. Grevendonk L, Connell NJ, McCrum C, Fealy CE, Bilet L, Bruls YMH, Mevenkamp J, Schrauwen-Hinderling VB, Jörgensen JA, Moonen-Kornips E, Schaart G, Havekes B, de Vogel-van den Bosch J, Bragt MCE, Meijer $\mathrm{K}$, Schrauwen P, Hoeks J (2021) Impact of aging and exercise on skeletal muscle mitochondrial capacity, energy metabolism, and physical function. Nat Commun 12 (1):4773. doi:10.1038/s41467-021-24956-2

61. Guralnik JM, Simonsick EM, Ferrucci L, Glynn RJ, Berkman LF, Blazer DG, Scherr PA, Wallace RB (1994) A short physical performance battery assessing lower extremity function: association with self-reported disability and prediction of mortality and nursing home admission. J Gerontol 49 (2):M85-94. doi:10.1093/geronj/49.2.m85

62. Dempster P, Aitkens S (1995) A new air displacement method for the determination of human body composition. Med Sci Sports Exerc 27 (12):1692-1697

63. van der Berg JD, Willems PJB, van der Velde JHPM, Savelberg HHCM, Schaper NC, Schram MT, Sep SJS, Dagnelie PC, Bosma H, Stehouwer CDA, Koster A (2016) Identifying waking time in 24-h accelerometry data in adults using an automated algorithm. J Sports Sci 34 (19):1867-1873. doi:10.1080/02640414.2016.1140908

64. Tudor-Locke C, Craig CL, Brown WJ, Clemes SA, De Cocker K, Giles-Corti B, Hatano Y, Inoue S, Matsudo SM, Mutrie N, Oppert JM, Rowe DA, Schmidt MD, Schofield GM, Spence JC, Teixeira PJ, Tully MA, Blair SN (2011) How many steps/day are enough? For adults. Int J Behav Nutr Phys Act 8 (1):79. doi:10.1186/14795868-8-79

65. Bergström J, Hermansen L, Hultman E, Saltin B (1967) Diet, Muscle Glycogen and Physical Performance. Acta Physiol Scand 71 (2-3):140-150. doi:10.1111/j.1748-1716.1967.tb03720.x

66. Koopman R, Schaart G, Hesselink MK (2001) Optimisation of oil red O staining permits combination with immunofluorescence and automated quantification of lipids. Histochem Cell Biol 116 (1):63-68. doi:10.1007/s004180100297

67. Schneider CA, Rasband WS, Eliceiri KW (2012) NIH Image to ImageJ: 25 years of image analysis. Nat Methods 9 (7):671-675. doi:10.1038/nmeth.2089

68. Hof AL, Gazendam MG, Sinke WE (2005) The condition for dynamic stability. J Biomech 38 (1):1-8. doi:10.1016/j.jbiomech.2004.03.025

69. McCrum C, Willems P, Karamanidis K, Meijer K (2019) Stability-normalised walking speed: A new approach for human gait perturbation research. J Biomech 87:48-53. doi:10.1016/j.jbiomech.2019.02.016

70. McCrum C, Karamanidis K, Grevendonk L, Zijlstra W, Meijer K (2020) Older adults demonstrate interlimb transfer of reactive gait adaptations to repeated unpredictable gait perturbations. Geroscience 42 (1):39-49. doi:10.1007/s11357-019-00130-x

71. McCrum C, Karamanidis K, Willems P, Zijlstra W, Meijer K (2018) Retention, savings and interlimb transfer of reactive gait adaptations in humans following unexpected perturbations. Commun Biol 1 (1):230. doi:10.1038/s42003-018-0238-9

72. McCrum C, Vaes AW, Delbressine JM, Koopman M, Liu W-Y, Willems P, Meijer K, Spruit MA (2022) A pilot study on the feasibility and effectiveness of treadmill-based perturbations for assessing and improving walking stability in chronic obstructive pulmonary disease. Clin Biomech 91:105538. doi:10.1016/j.clinbiomech.2021.105538

73. Gerards MHG, Meijer K, Karamanidis K, Grevendonk L, Hoeks J, Lenssen AF, McCrum C (2021) Adaptability to Balance Perturbations During Walking as a Potential Marker of Falls History in Older Adults. Front Sports Act Living 3:682861. doi:10.3389/fspor.2021.682861

74. Zeni JA, Jr., Richards JG, Higginson JS (2008) Two simple methods for determining gait events during treadmill and overground walking using kinematic data. Gait Posture 27 (4):710-714. doi:10.1016/j.gaitpost.2007.07.007

75. McCrum C, Lucieer F, van de Berg R, Willems P, Perez Fornos A, Guinand N, Karamanidis K, Kingma H, Meijer K (2019) The walking speed-dependency of gait variability in bilateral vestibulopathy and its association with clinical tests of vestibular function. Sci Rep 9 (1):18392. doi:10.1038/s41598-019-54605-0

76. Süptitz F, Moreno Catala M, Brüggemann GP, Karamanidis K (2013) Dynamic stability control during perturbed walking can be assessed by a reduced kinematic model across the adult female lifespan. Hum Mov Sci 32 (6):1404-1414. doi:10.1016/j.humov.2013.07.008

77. Süptitz F, Karamanidis K, Moreno Catala M, Bruggemann GP (2012) Symmetry and reproducibility of the components of dynamic stability in young adults at different walking velocities on the treadmill. J Electromyogr Kinesiol 22 (2):301-307. doi:10.1016/j.jelekin.2011.12.007

78. Cohen J (1992) A power primer. Psychol Bull 112 (1):155-159. doi:10.1037//0033-2909.112.1.155

79. Brydges CR (2019) Effect Size Guidelines, Sample Size Calculations, and Statistical Power in Gerontology. Innov Aging 3 (4):igz036. doi:10.1093/geroni/igz036

80. McKendry J, Breen L, Shad BJ, Greig CA (2018) Muscle morphology and performance in master athletes: A systematic review and meta-analyses. Ageing Res Rev 45:62-82. doi:10.1016/j.arr.2018.04.007

81. Zampieri S, Pietrangelo L, Loefler S, Fruhmann H, Vogelauer M, Burggraf S, Pond A, Grim-Stieger M, Cvecka J, Sedliak M, Tirpáková V, Mayr W, Sarabon N, Rossini K, Barberi L, De Rossi M, Romanello V, Boncompagni S, Musarò A, Sandri M, Protasi F, Carraro U, Kern H (2015) Lifelong physical exercise delays age-associated skeletal muscle decline. J Gerontol A Biol Sci Med Sci 70 (2):163-173. doi:10.1093/gerona/glu006

82. Pearson SJ, Young A, Macaluso A, Devito G, Nimmo MA, Cobbold M, Harridge SD (2002) Muscle function in elite master weightlifters. Med Sci Sports Exerc 34 (7):1199-1206. doi:10.1097/00005768-200207000-00023 
bioRxiv preprint doi: https://doi.org/10.1101/2021.11.26.470167; this version posted November 27, 2021. The copyright holder for this preprint (which was not certified by peer review) is the author/funder, who has granted bioRxiv a license to display the preprint in perpetuity. It is made available under aCC-BY 4.0 International license.

83. Coggan AR, Spina RJ, King DS, Rogers MA, Brown M, Nemeth PM, Holloszy JO (1992) Skeletal muscle adaptations to endurance training in 60- to 70-yr-old men and women. J Appl Physiol 72 (5):1780-1786. doi:10.1152/jappl.1992.72.5.1780

84. Cadore EL, Pinto RS, Bottaro M, Izquierdo M (2014) Strength and endurance training prescription in healthy and frail elderly. Aging Dis 5 (3):183-195. doi:10.14336/ad.2014.0500183

85. Hunter SK, Pereira HM, Keenan KG (2016) The aging neuromuscular system and motor performance. J Appl Physiol 121 (4):982-995. doi:10.1152/japplphysiol.00475.2016

86. Kadono N, Pavol MJ (2013) Effects of aging-related losses in strength on the ability to recover from a backward balance loss. J Biomech 46 (1):13-18. doi:10.1016/j.jbiomech.2012.08.046

87. Epro G, Mierau A, McCrum C, Leyendecker M, Bruggemann GP, Karamanidis K (2018) Retention of gait stability improvements over 1.5 years in older adults: effects of perturbation exposure and triceps surae neuromuscular exercise. J Neurophysiol 119 (6):2229-2240. doi:10.1152/jn.00513.2017

88. Oludare SO, Pater ML, Rosenblatt NJ, Grabiner MD (2018) Trip-specific training enhances recovery after large postural disturbances for which there is NO expectation. Gait Posture 61:382-386. doi:10.1016/j.gaitpost.2018.02.001

89. Pater ML, Rosenblatt NJ, Grabiner MD (2015) Expectation of an upcoming large postural perturbation influences the recovery stepping response and outcome. Gait Posture 41 (1):335-337. doi:10.1016/j.gaitpost.2014.10.026

90. Luden N, Minchev K, Hayes E, Louis E, Trappe T, Trappe S (2008) Human vastus lateralis and soleus muscles display divergent cellular contractile properties. Am J Physiol Regul Integr Comp Physiol 295 (5):R1593-R1598. doi:10.1152/ajpregu.90564.2008

91. Gollnick PD, Sjödin B, Karlsson J, Jansson E, Saltin B (1974) Human soleus muscle: a comparison of fiber composition and enzyme activities with other leg muscles. Pflugers Arch 348 (3):247-255. doi:10.1007/bf00587415

92. Edgerton VR, Smith JL, Simpson DR (1975) Muscle fibre type populations of human leg muscles. Histochem J 7 (3):259-266. doi:10.1007/bf01003594 